\title{
ESTADO E EDUCACÃO: A FORMAÇÃO DE PROFESSORES EM QUESTÃo
}

\author{
STATE AND EDUCATION: THE TEACHER TRAINING \\ ESTADO Y EDUCACIÓN: LA FORMACIÓN DE PROFESORES
}

RESUMO: O artigo analisa a formação de professores no contexto do Parecer no $009 / 2001$ do Conselho Nacional de Educação, aprovado em 8/5/2001 e instituído pela Resolução n⿳o 01/2002, de 18/2/2001, do Conselho Nacional de Educação/Conselho Pleno. São analisados: o contexto justificador das reformas, com ênfase na adequação do sistema educativo aos ditames do ideário neoliberal; a nova função social da escola e o papel dos professores, chamando a atenção para a nova lógica desse processo; e o problema da qualificação profissional do magistério no contexto universitário.

PALAVRAS-CHAVE: Estado. Educação. Formação de professores. Escola. Universidade.

ABSTRACT: The paper analyzes Teachers' Training in the Opinion context 009/2001 of the National Council of Education, adopted on 05/08/2001 and established by Resolution 01/2002 on 02/18/2001 - National Council of Education/Full board. There is an analysis of Reforms justifying context, emphasizing the educational system adequacy to the neoliberal ideology, the new social function of school and teachers' role, drawing attention to the new logic of this process, and also, the teaching profession qualification problem at the University context.

KEYWORDS: State. Education. Teachers' training. School. University

RESUMEN: El artículo analiza la Formación de Profesores en el contexto del Parecer No. 009/2001 del Consejo Nacional de Educación, aprobado el 08/05/2001 e instituido por la Resolución No. 01/2002 del 18/o2/2001 - Consejo Nacional de Educación/Consejo Pleno. Se analiza el contexto justificador de las Reformas, com énfasis en la adecuación del sistema educativo a los dictámenes del ideario neoliberal, la nueva función social de la escuela y el papel de los profesores, llamando la atención para la nueva lógica de ese proceso, y también, el problema de la calificación profesional del magisterio en el contexto de la Universidad.

PALABRAS CLAVE: Estado. Educación. Formación de profesores. Escuela. Universidad. 
* Doutor em História Social pela Pontifícia Universidade Católica de São Paulo, Pós-Doutor na Universidade Técnica de Lisboa, Professor do Departamento de Metodologia de Ensino da Universidade Federal de Santa Catarina, Professor de História da Educação, Teoria e Metodologia do Ensino de História, curso de Pedagogia e História.

\section{INTRODUÇÃO}

A temática sobre a formação de professores somente pode ser entendida se compreendermos as atuais reformas como um conjunto orgânico de diretrizes que compõe as diversas partes de um projeto político no qual a educação ocupa um lugar estratégico.

O Estado brasileiro, pressionado pelo péssimo desempenho de sua Educação Básica e necessitando adequar-se aos processos de reestruturação de sua economia, tem implantado, desde o início do ano 2000, uma série de reformas com o intuito de melhorar a qualidade de sua educação, e tem na formação de professores um dos principais pilares.

Em 2001, o Conselho Nacional de Educação aprovou as Diretrizes Curriculares Nacionais para a Formação de Professores da Educação Básica em Nível Superior, em Curso de Licenciatura de Graduação Plena, através do Parecer no 009/2001, instituído pela Resolução no 01/2002 e aprovado em 8 de maio de 2001.

O que essas diretrizes conceituais e ideológicas apresentam de novo é exatamente o fato da subordinação de todo o sistema educacional a um fim único dentro de uma estratégia de poder bem definida nos quadros da própria reestruturação das relações capitalistas no País, marcada pelas práticas neoliberais de condução do processo produtivo.

Todavia, o que notamos hoje é que tal debate está sendo feito sem que seja levado em consideração o seu caráter orgânico. Com isso, acabou-se criando o consenso da necessidade de investir em uma formação de professores desvinculada de seu aspecto estrutural estratégico dentro do sistema, perdendo, assim, seu significado político.

Um exemplo claro dessa distorção é a discussão sobre a formação desvinculada: (a) da desqualificação social e material do magistério; (b) da autonomia do trabalho docente na escola pública; (c) das condições didáticas pedagógicas; (d) da reestruturação dos espaços escolares; (e) de bibliotecas; e (f) do papel político desse profissional, reduzido mais uma vez, como veremos, a um sujeito capaz de vulgarizar com competência o conhecimento científico produzido pelas torres de marfim do saber acadêmico.

O que está por trás disso é uma concepção de trabalho docente e de professor como transmissor e vulgarizador de conhecimento, caracterizado pelo conceito de transposição didática do saber escolar, bem ao gosto dos mentores da sociedade do conhecimento.

Debater a questão da formação de professores é, portanto, desnudar o projeto de poder que se vislumbra nessa concepção de formação e seus efeitos nefastos para o conjunto da sociedade.

Do ponto de vista político, tais diretrizes materializam o projeto da burocracia estatal e dos intelectuais cooptados pelo ministério da educação e cultura, saídos dos quadros da própria universidade, que desempenham hoje papel fundamental no cotidiano acadêmico, na consolidação 
de tais medidas, as quais transformaram a universidade em um gigantesco mercado persa, através de fundações e convênios com a iniciativa privada.

Por outro lado, cabe salientar também, como apontou Oliveira (2000), que o debate em torno da educação na década de 1990 se renovou e se intensificou a partir das discussões sobre as exigências de um padrão de qualificação emergente no contexto da reestruturação produtiva e da globalização da economia, no qual se explicitou a necessidade de se repensar e de se propor alternativas para problemas estruturais da educação brasileira, passando necessariamente pela reforma dos sistemas públicos de ensino.

Porém, ao mesmo tempo em que se mergulha no debate em torno do novo papel da educação no contexto da reestruturação produtiva do capitalismo, pouco se discute a respeito das profundas transformações ocorridas na sociedade brasileira desse período, marcadas por uma reordenação dos grupos de poder, por novos compromissos, alianças e pela opção de desenvolvimento, assumidos pelos atuais mandatários do País, com os resultados que hoje colhemos.

Nesse sentido, o papel central que a discussão no campo da educação ao longo dos anos 1990 vai ocupar é a incorporação definitiva do ideário neoliberal nos currículos e nas propostas de formação de professores, alimentando a crença na educação como fator de equidade social, levando mais uma vez a expandir enormemente as oportunidades educacionais e a reformar as instituições escolares, que, na relação custo-benefício, representam um custo menor do que a alteração da distribuição de renda e relações do poder (XAVIER, 1990).

As Diretrizes Curriculares Nacionais para a formação de professores é apenas mais uma faceta desse processo. Este artigo analisa tais diretrizes, com destaque ao contexto que as justificam; a nova função social da escola; o papel dos professores e o problema da qualificação social.

\section{AS DIRETRIZES CURRICULARES NACIONAIS PARA A FORMAÇÃO DE PROFESSORES DA EDUCAÇÃO BÁSICA EM NÍVEL SUPERIOR - CURSO DE LICENCIATURA DE GRADUAÇÃO PLENA}

Como frisamos no início desta exposição, as Diretrizes Curriculares Nacionais para a formação de professores fazem parte de um conjunto orgânico de outras resoluções que tendem a estruturar o sistema educacional, sendo a formação dos professores um ponto estratégico dentro desse conjunto, pois altera fundamentalmente a organização da universidade brasileira e a estrutura de seus cursos de licenciatura e bacharelado, propondo-lhes uma nova configuração.

A publicação dessas diretrizes coroa um processo desencadeado pelo Ministério da Educação e pelo Conselho 
Nacional de Educação, que visava adequar a formação de profissionais ao atendimento das demandas de um mercado globalizado. Por sua vez, considerando-se os objetivos postos pelas reformas da Educação Básica no sentido de adequar a formação das novas gerações às exigências postas pelas transformações do mundo do trabalho, o conteúdo e a organização das instituições de formação de professores passam a ter sua centralidade para garantir o desenvolvimento da educação básica tal como está postulada (FREITAS, 2002).

Para Helena Costa Lopes de Freitas (2002), o processo de constituição de tais diretrizes expressa as contradições presentes nas atuais formulações sobre formação de professores, trazendo à tona os dilemas e as dicotomias do processo, tais como professor versus generalista, professor versus especialistas e especialistas versus generalistas.

O encaminhamento dado pelo Ministério da Educação (MEC) reforçou essas dicotomias, constituindo em primeiro lugar as comissões encarregadas da elaboração das diretrizes dos distintos bacharelados; somente ao seu término estabeleceu comissão, no âmbito do próprio MEC, para elaborar as diretrizes para a formação de professores (FREITAS, 2002, p. 151).

Ainda no que se refere ao processo de constituição das diretrizes, o documento final, ao mesmo tempo em que incorporou reivindicações históricas do movimento docente, acabou limitando as possibilidades de ação das instituições, ao reduzir, por exemplo, a carga horária prevista, aligeirando a formação.

Após um pequeno preâmbulo, no qual o texto procura dar a impressão de que as diretrizes foram fruto de um amplo processo de discussão com as entidades mais representativas do campo educacional, passa, então, a explicitar suas bases conceituais e a justificar as suas proposições.

Para uma melhor compreensão dos aspectos fundamentais do parecer, analisaremos o texto a partir de algumas questões centrais.

\section{O CONTEXTO JUSTIFICADOR DAS REFORMAS}

Uma característica marcante das atuais reformas em curso na educação brasileira, incluindo aí também as atuais Diretrizes para a Formação de Professores, é o seu discurso neutro, asséptico, despolitizado e, acima de tudo, desestoricizado, pois faz silêncio absoluto dos processos históricos que o engendraram.

No que tange ao parecer, lemos:

A democratização do acesso e a melhoria da qualidade da educação básica vem acontecendo num contexto marcado pela redemocratização do país e por profundas mudanças nas expectativas e demandas educacionais da sociedade brasileira. $\mathrm{O}$ avanço e a disseminação das tecnologias de informação e da 
comunicação está impactando as formas de convivência social, de organização do trabalho e do exercício da cidadania. A internacionalização da economia confronta o Brasil com a necessidade indispensável de dispor de profissionais qualificados. Quanto mais o Brasil consolida as instituições políticas democráticas, fortalece os direitos de cidadania e participa da economia mundializada, mas se amplia o reconhecimento da importância da educação para a promoção do desenvolvimento sustentável e para a superação das desigualdades sociais. (BRASIL, 2001, p. 3-4).

Um exame mais atento de tais premissas, no entanto, nos remete a alguns questionamentos. Em primeiro lugar, destaca-se o fato da relação entre o processo de democratização do País durante a década de 1980 e a democratização do acesso e melhoria da qualidade da educação básica.

Ora, como sabemos, o processo de redemocratização da sociedade brasileira, ao longo da década de 1980, foi marcado por profundas contradições do ponto de vista das alternativas propostas para a sociedade brasileira. A multiplicidade de interesses fez com que esse processo se realizasse a partir de um intrincado jogo de forças que marcou os seus limites.

Por outro lado, um forte movimento social marcado por reivindicações, greves do magistério em todo País, a constituinte de 1988, movimentos em torno da reestruturação curricular, embates contra os resquícios autoritários da Lei n⿳o $5.692 / 72$ e esforços de várias administrações estaduais com propostas democráticas garantiram um mínimo de democratização à educação nesse período, que, nos primeiros anos da década de 1990, foram sufocados pelas novas Diretrizes e Bases da Educação Nacional (LDB no 9394/96).

No que se refere ao impacto e avanço das tecnologias de informação e comunicação nas formas de organização social e reestruturação do trabalho, a situação é mais complexa, pois, se pensarmos no que esse impacto nas formas de convivência social e organização de trabalho significa, vamos nos deparar, entre outras coisas, com o desemprego, a exclusão e a miséria social.

Dessa forma, como salientou Luiz Fernandes Dourado (2002), a inserção do País na lógica neoliberal como coadjuvante no processo de globalização em curso, sintonizado com as premissas de liberalização econômica, desregulação financeira, alterações substantivas na legislação previdenciária e trabalhista, e, fundamentalmente, na intensificação dos processos de privatização da esfera pública, tem sido apresentada pelos setores dirigentes como um claro indicador de modernização do Estado patrimonial. A perspectiva neoliberal é, nesse contexto, ideologicamente difundida apenas como reformulação da gestão do desenvolvimento capitalista, na qual a desigualdade é aceita 
como norma e o desemprego, como contingência necessária ao desenvolvimento do capital.

No que tange ao avanço das tecnologias, estas se tornaram uma grande panaceia, juntamente com a disseminação de que vivemos sob o paradigma de uma sociedade do conhecimento.

A ênfase ideológica dada a esses processos revela a mística de que resultam do advento tecnológico, e não de opções econômicas e políticas que têm o mercado como portador de racionalidade e modelador das formas de organização social (DOURADO, 2002).

Tais tecnologias não se apresentam como simples veículos da ideologia dominante ou ferramentas de entretenimento puro e inocente; são produzidas e apropriadas socialmente, incorporando e disseminando discursos sociais e políticos (DOURADO, 2002).

Nesse contexto, como salientou Marilena Chaú (1999), na nova configuração do capitalismo nos anos de 1980 e 1990, em primeiro lugar, a ciência e a técnica tornaram-se, sobretudo, forças produtivas, deixando de ser meros suportes do capital para se converter em agentes de sua acumulação, de forma que se transforma radicalmente a maneira que técnicos e cientistas se inserem na sociedade, uma vez que estes se tornam agentes econômicos diretos, e a força e o poder do capitalista encontra-se no monopólio dos conhecimentos e da informação.

Por sua vez, se tomarmos o impacto sob as formas de convivência social, como o desemprego estrutural e o profundo processo de exclusão social que isso acarreta, tal processo não é somente fruto da introdução da automação no processo produtivo, mas também da enorme velocidade da rotatividade da mão de obra, que se torna desqualificada e obsoleta rapidamente diante da velocidade das mudanças tecnológicas (CHAUÍ, 1999).

Assim, quando se propaga a necessidade de rever a formação de professores, baseada no fato de que a disseminação e o avanço das tecnologias da informação e comunicação estão impactando as formas de convivência social, organização do trabalho e exercício da cidadania, como advogam as diretrizes que ora analisamos, sem, contudo, levar em consideração o momento histórico constituinte dessa relação, mascaram-se as relações sociais que as engendraram.

Pensar, pois, a formação de professores nesse contexto significa entendê-la em suas múltiplas dimensões e significações, uma vez que:

[...] implica romper com a mística que acentua o papel das tecnologias da informação e comunicação (TIC) como protagonistas sociais, remetendo ao necessário desvelamento do Estado em sentido amplo, entendido como espaço de luta política e expressão da condensação de forças entre sociedade civil e política, e de sua materialização no campo das 
políticas engendradas e materializadas pelo Estado na sociedade. Ou seja, é fundamental romper com a naturalização de concepções e sistemas políticos como se fossem meras decorrências de inflexões de bases digitais ou resultantes da pretensa hegemonia assumida pelos recursos midiáticos. Ao mesmo tempo, implica não perder de vista a complexidade do cenário sócio-político em que as TIC assumem papel significativo, como veículo formativo, tendo em vista que imagens, sons, narrativas fornecem símbolos, mitos e recursos que favorecem a constituição do senso comum desagregado e funcional. (DOURADO, 2002, p. 239).

Outro aspecto presente na justificativa básica das reformas refere-se à necessidade de mão de obra qualificada para fazer frente ao processo de internacionalização da economia brasileira para participar de uma economia globalizada.

Se examinarmos mais atentamente essa questão, vamos perceber que a inserção do País no contexto do capitalismo internacional nos anos 1990 se constituiu em uma opção política deliberada dos grupos que assumiram o poder com a eleição de Fernando Henrique Cardoso, cujo modelo de desenvolvimento adotado se caracterizou pela internacionalização da economia brasileira; sua subordinação ao capital especulativo internacional; desnacionalização do parque industrial brasileiro; desmantelamento e cooptação da estrutura sindical e um terrível arrocho salarial.

Finalizando o rol das justificativas da reforma, temos a educação como um fator de promoção do desenvolvimento sustentável e superação das desigualdades sociais.

Quanto à educação como fator de superação das desigualdades sociais e como forma de mobilidade social, ideia amplamente explorada pelo liberalismo capitalista e pela teoria do capital humano, ela foi acentuada a partir da Conferência Mundial sobre Educação para Todos, realizada na Tailândia, em 1990, na qual a preocupação com a educação dirigida à equidade social passou a orientar as recomendações dos organismos internacionais ligados à Organização das Nações Unidas (ONU) para as políticas educacionais dos países pobres e mais populosos do mundo.

As reformas educacionais nos anos 1990 terão, portanto, essa finalidade (OLIVEIRA, 2000, p. 21). Todavia, é preciso cuidado com tal preocupação, visto que, como nos alerta Torres Santomé (1996), o perigo de se voltar ao mito da educação como compensação de todas as desigualdades sociais e reinventá-lo está em cada esquina, e é central ter isso em nosso ponto de mira, pois, ainda que seja óbvio que o sistema educativo tem grandes problemas, não é menos importante o fato de que nunca, como neste momento histórico, houve um excesso tão notável de "supereducação". A maioria imensa dos postos de trabalho está ocupada por homens e mulheres com um excesso de habilidades e 
conhecimento em relação às demandas de tais lugares de trabalho.

Todavia, a educação como forma de superar as desigualdades sociais ainda guarda outra dimensão fundamental, quando analisada em uma perspectiva socioeconômica, pois parte de uma indicação de que:

[...] as imperfeições da sociedade como um todo decorrem, afinal, da ignorância ou dos baixos níveis de cultura do 'povo', das pessoas e devem ser resolvidas a partir da remoção dessas "causas", isto é, dando-se educação ao 'povo'. Para corroborar essa linha de pensamento com base em demonstrações estatísticas, prova-se que os países onde a educação escolar é mais desenvolvida e generalizada são aqueles que apresentam maior progresso econômico e social, que a pessoa educada percebe maiores salários que o analfabeto, e que uma pessoa com maior número de anos de escolaridade ganha mais do que outra com menos. (ROSSI, 1980, p. 17).

A par das controvérsias que tal afirmação pode causar, o fato é que o esforço das autoridades educacionais brasileiras em bombardear a sociedade e os meios de comunicação com as avaliações de desempenho acerca da Educação Básica, na tentativa de mostrar: (a) o aumento das matrículas; (b) os índices de escolarização; (c) o tempo de permanência na escola; (d) o crescimento do Ensino Médio; e (e) o aumento do número de doutores nas universidades, põe às claras o peso que esses discursos têm na formulação das atuais políticas públicas em torno da educação no Brasil.

Essa questão não é menos complexa se levarmos em consideração o tão propagado desenvolvimento sustentável. Mas o que implica tal ideia, em um currículo de formação de professores?

O termo "desenvolvimento sustentável", segundo Francisco Milanez (2003), surgiu ainda nos anos 1980, como uma reação ao agravamento da situação ambiental planetária, consequência, segundo o autor, da corrida suicida pelo crescimento econômico que devastava os recursos naturais e que começava a causar destruições e mortes. Esse autor ressalta também que o fracasso das ações iniciais para se conter a crise, as quais eram embasadas somente na diminuição da poluição nas atividades humanas, fez a ONU criar uma comissão mundial sobre meio ambiente e desenvolvimento e encomendar um estudo apresentado em 1987 com o nome de "Nosso Futuro Comum".

Esse estudo passou a ser conhecido também por "Relatório Brundtland”, nome do presidente de tal comissão, e foi nele que apareceu oficialmente o termo desenvolvimento sustentável, definido como "[...] aquele que atende às necessidades do presente sem comprometer a possibilidade das gerações futuras atenderem suas próprias necessidades" (MILANEZ, 2003, p. 77). 
Mas quais são as bases desse desenvolvimento sustentável e qual sua relação com a Educação?

A primeira categoria a sustentar a ideia de desenvolvimento sustentável é o conceito de cultura. Nessa perspectiva,

[...] o desenvolvimento deve ser culturalmente respeitoso. [...]. Não é possível comunidade alguma alcançar sua realização se não tomar como base sua cultura. [...]. Elas constituem o acúmulo dos conhecimentos das sociedades em determinados meios ambientes através dos tempos. Fazem parte dela os sistemas de valores, as estratégias de produção, as formas de laser, as crenças religiosas as expressões artísticas, cientificas, filosóficas e tantas outras que são totalmente co-evolutivas interdependentes, indispensáveis para a realização das pessoas e expressões diretas do meio onde foram forjados. (MILANEZ, 2003, p.80).

A esse respeito, algumas considerações são de extrema importância. Em primeiro lugar, caberia a questão: o que seria um desenvolvimento cultural respeitoso?

Ora, sabemos que, ao longo de quase toda a história humana, nunca houve desenvolvimento sem massacre, dominação, destruição ou mesmo a eliminação física e cultural de povos ou até mesmo de civilizações inteiras ou, para empregar o termo em uso, do "outro".

Um exemplo claro disso é a própria história do Brasil, cujo processo de colonização foi responsável pela devastação da quase totalidade do litoral brasileiro, além do extermínio de milhares de índios e negros escravizados.

Atualmente são as "fronteiras agrícolas", que avançam pelo interior do País, as responsáveis pelas catástrofes ambientais.

O século XX no Brasil é cheio de exemplos que mostram como o desenvolvimento, em nome do progresso e da civilização, destruiu e jogou na miséria populações inteiras, despojando-as de suas tradições culturais, crenças e valores religiosos.

A reforma urbana da cidade do Rio de Janeiro, levada a efeito pelo então prefeito Pereira Passos ainda nas primeiras décadas do século XX, e a abertura da rodovia Transamazônica nos anos 1970 pelos governos militares são expressões claras dessa impossibilidade de "desenvolvimento cultural respeitoso".

Ademais, cabe salientar que, desvincular o desenvolvimento e a destruição ambiental de sua relação com a geopolítica; do interesse das nações; de uma economia global dos mecanismos de destruição em massa dos processos técnicos científicos é, no mínimo, uma má-fé descabida do mundo politicamente correto.

Uma segunda aberração diz respeito ao fato de se expulsar da história o homem como produtor de sua cultura e substituí-lo pela própria cultura. 
A cultura é fruto das relações humanas, do homem vivendo em sociedade e datada historicamente. É, acima de tudo, socialmente construída no tempo e espaço, determinante e determinada pelas relações sociais de produção que os homens desenvolvem para satisfazer suas necessidades históricas, e o meio constitui apenas mais um elemento dessa complexa relação.

Por outro lado, o suposto "determinismo ecológico e geográfico" implícito nessa abordagem serve, a nosso ver, para mascarar e mistificar as reais relações de dominação e poder que se constituem entre as classes sociais e justificadoras da conservação da ordem.

É na sua relação com a educação, porém, que esse conceito revela a sua essência. O longo trecho a seguir nos é extremamente esclarecedor quanto a essa questão:

O desenvolvimento sustentável busca a construção de sociedades felizes, em harmonia com seu meio ambiente. Para que sejam operadas estas mudanças, precisamos de pessoas confiantes na possibilidade de alcançar estes câmbios e que tenham uma excelente imagem de si mesmas e de suas comunidades. Esta autoimagem só se constrói através de uma Educação que ao mesmo tempo desenvolva indivíduos críticos criativos e cooperativos. Somente da junção de milhares de pessoas seguras, teremos as ideias necessárias para corrigir os rumos de nossas sociedades. Por isso são necessárias construções coletiva e grande capital social. Revisões de valores, costumes, formas de ver e julgar as coisas, são esforços hercúleos para construção de um novo paradigma, que só se realizam cooperativa e coordenadamente. Uma forma de participação inclusiva é indispensável para superar esse desafio. Uma nova forma de gerenciamento de nossas atividades sociais terá de ser gestada também. (MILANEZ, 2003, p. 81).

Como podemos observar, estão aí reunidas as "asneiras mais sofisticadas" dos mentores da responsabilidade social.

Nenhuma palavra é mencionada sobre exploração, trabalho, desigualdade social. Os problemas da humanidade agora estão resumidos na busca individual pela felicidade, que se resume na ideia de que, se as pessoas fizerem cada uma a sua parte, resgatando sua autoestima, poderão mudar o mundo, gestando suas atitudes com responsabilidade social.

Nesse mundinho feliz e sem contradição, cabe perguntar: quem trabalharia e produziria as riquezas para esse seleto grupo de felizardos alcançar o paraíso terrestre?

O festival de besteiras, no entanto, não acaba por aí, pois esse mundinho seria criado por uma nova educação, que levaria todos à felicidade suprema: 
A construção dessa nova sociedade passa necessariamente por uma revisão na forma como produzimos os conhecimentos e de como educamos. Sem uma sociedade que permita a todos contribuírem crítica e criativamente na solução dos problemas, na construção dos conhecimentos e na educação de todos, não é possível imaginar como alcançar a cumplicidade que requer um pacto social e as mudanças de costumes e valores necessários. Grande parte do empecilho para alcançar este objetivo está na forma arrogante e elitista com que se constroem os conhecimentos, bem como na forma limitada e a crítica com que são divulgados, seja pelos meios de comunicação, seja por uma educação alienante. (MILANEZ, 2003, p. 81).

Mas cabe aqui a questão: a que sociedade se refere o autor? Que conhecimentos são esses a que ele se reporta? Quais problemas devem ser solucionados? A que pacto social ele se refere? De que elitismo e arrogância ele está falando? O que é uma educação alienante? Como podemos depreender, as respostas a essas questões não se encontram ao vento, e sim no "mercado"!

\section{A NOVA FUNÇÃO DA ESCOLA E O PAPEL DOS PROFESSORES}

Como vimos no tópico anterior, a premissa básica da qual parte o texto do parecer refere-se a processos históricos complexos, que em nenhum momento são explicitados na fala dos legisladores.

Tendo como base tais constatações, esse parecer reforça concepções expressas em documentos anteriores, como os Parâmetros Curriculares Nacionais, em que se destaca a ideia da construção de uma cidadania capaz de oferecer aos estudantes as bases culturais que lhes permitam inserção na vida produtiva e sociopolítica do País.

No que tange à nova função da escola no contexto social, lemos:

[...] estudos têm-se concentrados na questão da abertura e do enraizamento da escola na comunidade, como imposição dos novos tempos. [...].Se a abertura das escolas à participação da comunidade é fundamental, da mesma forma, as instituições formadoras precisam penetrar nas novas dinâmicas culturais e satisfazer as demandas sociais apresentadas à educação escolar. (BRASIL, 2001, p. 3-4).

Aqui é preciso destacar duas questões. A primeira é o fato de que, por imposição sabe-se lá de que "novos tempos", as instituições formadoras, leia-se universidades, têm o papel de "satisfazer as demandas" da educação escolar, 
subordinando, assim,a formação de professores aos objetivos da educação básica, perspectiva essa que deixa transtornados os mentores da universidade voltada para a "pesquisa" e que desconhece totalmente as questões complexas da difusão do conhecimento. Além disso, não assume a responsabilidade pela mão de obra que passa nos seus bancos escolares.

Por sua vez, ainda, a expressão "satisfazer as demandas" marca a preocupação com os processos de gestão da educação, que, combinados à centralização das decisões com a descentralização das ações, ampliam a autonomia administrativa e financeira das unidades escolares, cujo eixo central se assenta na racionalidade administrativa, tendo como paradigma a lógica da economia privada, sendo dentro desse princípio que se justifica a escola voltada para a comunidade (OLIVEIRA, 2000).

Porém, o que se estaria entendendo por comunidade?

Em primeiro lugar, há que se colocar a própria ideia de escola, reconhecida socialmente como instituição depositória dos saberes historicamente construídos, que desenvolve uma prática educativa planejada e sistemática durante um período contínuo e extenso de tempo. Todavia, até bem pouco tempo a escola se constituía em um espaço venerado por pais e alunos; de disciplina rígida, limpeza asséptica, lugar de civilizado, e a comunidade permanecia distante e isolada de seu contexto, cabendo a ela muito pouco na sua existência cotidiana.

A partir da década de 1970, observou-se, porém, uma gradual democratização do ensino com o crescente número de matrículas nos três níveis escolares, marcando a inserção de um contingente social novo na escola, sem, contudo, influir decisivamente na melhoria de sua qualidade.

Hoje, um dado significativo é a deterioração de grande parte da rede oficial de ensino, que não está adequada para receber esse contingente cada vez maior de alunos e nem possui as condições pedagógicas necessárias ao trabalho escolar, contradizendo as estatísticas oficiais.

$\mathrm{E}$ aqui voltamos à comunidade. Em princípio, o discurso da comunidade revela a completa falta de responsabilidade do Estado com a manutenção das condições pedagógicas para a realização do trabalho escolar.

Por sua vez, esta se insere na atual estratégia do governo federal, na qual a descentralização dos serviços essenciais se constitui em um modo de aumentar a eficiência e a eficácia dos gastos públicos, aumentando as possibilidades de interação, no nível local, dos recursos públicos e dos não governamentais para o financiamento das atividades sociais. Basta observarmos a quantidade infindável de organizações da iniciativa privada e não governamentais que atuam na área educacional.

Por fim, é a própria noção de comunidade que está em jogo, pois, como salientou Marilena Chaú (1980), o que se entende por comunidade em uma sociedade de classes? Quem são os representantes da comunidade junto à 
escola? Quais serviços a escola deve prestar à comunidade? Nas escolas de primeiro e segundo graus, quem é a comunidade?

Assim, após definir a nova função da escola no contexto social, as novas tarefas dos professores da educação infantil e do ensino médio, o parecer se atém a novas tarefas da universidade no tocante à formação docente:

[...] impõe-se à revisão da formação docente em vigor na perspectiva de fortalecer ou instaurar processos de mudança no interior das instituições formadoras, respondendo às novas tarefas e aos desafios apontados, que incluem o desenvolvimento da disposição para a atualização constante de modo a iterar-se dos avanços do conhecimento nas diversas áreas, incorporando-os, bem como aprofundar a compreensão da complexidade do ato educativo em sua relação com a sociedade. (BRASIL, 2001, p. 10).

À primeira vista, quando lemos as afirmações acima, o que nos chama a atenção é a profunda amnésia histórica dos autores do documento em questão.

Obviamente a universidade pública brasileira possui profundas distorções, e aqui não se trata de negá-las, pois não é objetivo deste texto, mas o parecer desconhece e não faz nenhuma referência a tais processos, pois são negadas todas as contribuições da universidade, a qual é tratada como algo anacrônico, desatualizado e sem ter nenhuma relação com o mundo que a circunda.

O que está em jogo aqui, mais uma vez, é o profundo descaso com aqueles que construíram a universidade pública no País, ou seja,

[...] os docentes que se dedicam ao ensino e à pesquisa em tempo integral, dependem inteiramente dos recursos públicos... destinam a totalidade de seus trabalhos à sociedade, seja formando profissionais de várias áreas, seja formando novos professores, seja publicando suas pesquisas e a de seus estudantes, seja realizando atividades de extensão universitária para profissionais de várias áreas e para atualização de professores de primeiro e segundo graus, seja realizando pesquisas ou participando na formulação e supervisão de projetos e programas sociais para os governos. (CHAUÍ, 1980, p. 39-40).

Ainda com relação à "revisão da formação docente em vigor", apontada pelo parecer, cabe acrescentar que, há décadas, a sociedade brasileira e as entidades ligadas ao magistério e aos movimentos sociais, de maneira geral, denunciam o descaso histórico do País com a educação pública e a política de exclusão social patrocinada por uma escola longe das aspirações da sociedade brasileira.

Há mais tempo, ainda, são apontados os descasos em relação à formação e qualificação dos professores e o 
desmonte sucessivo das condições de trabalho nas escolas e universidades do País. O resultado disso foi a explosão, nas universidades públicas e particulares, de cursos e linhas de pesquisa, tanto nas especializações e pós-graduações, dedicados à questão da formação de professores.

Cabe ressaltar que não estamos negando a necessidade de se rever a formação dos profissionais da educação e nunca se negou a contribuição indireta e muitas vezes direta dos profissionais do magistério na construção da exclusão social, com sua omissão e falta de compromisso com outra perspectiva de educação.

Porém, ao assumirmos o discurso sobre a necessidade de reformar as instituições formadoras de professores e seus cursos, assinamos o próprio atestado de culpa, uma vez que, como veremos, nessa concepção de formação, a responsabilidade do processo recai inteiramente no professor, redime os profissionais não comprometidos com a educação, justifica a existência das escolas privadas em todos os níveis, apaga da memória social o descalabro histórico com a educação, justifica a crença no mercado de bens educacionais, pois, se a universidade pública e a escola básica não prestam, há que se deixar a mão invisível do mercado atuar sobre a sociedade, possibilitando uma maior oferta educacional, visto que a universidade não está preparada para as novas demandas do social desse mundo moderno, que exige uma formação cada vez mais flexível e adaptável, como é a denominada sociedade da informação e do conhecimento.

Nenhuma palavra sobre as condições materiais de existência dos profissionais da educação. Nessa versão do capitalismo, os seres humanos são apenas um detalhe descartável.

\section{O PROBLEMA DA QUALIFICAÇÃO PROFISSIONAL}

O problema da qualificação dos profissionais da educação sempre se constituiu uma questão séria e delicada no contexto da educação pública no País. No caso das instituições de ensino superior, isso vem tornando-se cada vez mais crítico em função da crescente mercantilização da educação e do corte abrupto dos investimentos.Os dados são assustadores em todos os sentidos.

A Revista Exame, em sua edição 763, de 3 de abril de 2002, publicou uma reportagem cujo título sugestivo "O Meganegócio da Educação" afirmava que a educação já movimentava cerca de 90 bilhões de reais por ano no Brasil, representando cerca de 9\% do PIB do País, o triplo do setor energético.

Esses dados, no entanto, se contrapõem de forma assustadora com as declarações da Associação Nacional dos Dirigentes das Instituições de Ensino Superior (Andifes), que apontava o decréscimo de investimentos no ensino superior público, na ordem de mais de $72 \%$. 
Por outro lado, os dados da Andifes apontam que, no período de 1995 a 2002, os recursos para a manutenção das Instituições Federais de Ensino Superior (IFES) caíram $17 \%$, mas sua oferta de vagas foi ampliada em $26 \%$, passando de 88 mil a 112 mil alunos no período.

Como se vê, ao mesmo tempo em que aumentou a demanda, houve um corte drástico nas verbas de manutenção e investimento.

Esse estudo da Andifes revela dados ainda mais assustadores. Segundo ele, o déficit de professores girava em torno de sete mil vagas e o de servidores técnicos e administrativos já chegava a 20 mil.

De acordo com dados da própria Secretaria do Ensino Superior do Ministério da Educação (SESU), hoje um em cada cinco professores é temporário, ou seja, 8 mil dos 40 mil docentes. Isso reflete a redução no número de concursos que, no período citado, também despencou de 440 em 1995 para 71 em 2000 (APUFSC, 2002).

Porém, o Conselho Nacional de Educação e seus burocratas parecem desconhecer tal fato e argumentam que a grande dificuldade para se implementar políticas públicas na área educacional refere-se ao:

[...] preparo inadequado dos professores cuja formação de modo geral manteve-se predominantemente um formato tradicional que não contempla muitas das características consideradas, na atualidade, como inerentes à atividade docente. (BRASIL, 2001, p. 4).

Mas quais seriam essas características? Segundo o parecer, elas se resumiriam neste conjunto de pré-requisitos:

[...] a) orientar e mediar o ensino para a aprendizagem dos alunos; b) comprometer-se com o sucesso da aprendizagem dos alunos; c) assumir e saber lidar com a diversidade dos alunos; d) incentivar atividades de enriquecimento cultural; e) desenvolver práticas investigativas; f) elaborar e executar projetos, para desenvolver conteúdos curriculares; g) utilizar novas metodologias, estratégicas e materiais de apoio; h) desenvolver hábitos de colaboração e trabalho em equipe. (BRASIL, 2001, p. 4).

Aqui é interessante perceber a quem o Ministério culpa pela sua incapacidade de levar adiante as políticas públicas no setor educacional.

Em primeiro lugar, a universidade é "tradicional", sem, no entanto, definir o que seja este preparo inadequado dado aos professores; e o argumento considerado é que os profissionais formados pela universidade não estão adequados às exigências dos "novos tempos". Além do mais, tais exigências expressam a extensa verborreia teórica e metodológica presente nas orientações curriculares, como: 
"ensino através de projetos"; "respeito à identidade e diversidade"; "ensino voltado e centrado na aprendizagem dos alunos"; "uso de novas tecnologias no processo educativo"; "gestão de conflitos"; "trabalho em equipe" etc.

Para que se crie esse profissional dos "novos tempos", é preciso, contudo, uma profunda revisão nos aspectos essenciais na formação inicial dos professores, que seriam,

[...] a organização institucional, a definição e estruturação dos conteúdos para que respondam as necessidades da atuação do professor, os processos formativos que envolvem aprendizagem e desenvolvimento das competências do professor, a vinculação entre as escolas de formação inicial e os sistemas de ensino de modo a assegurar-lhes indispensável preparação profissional. (BRASIL, 2001, p. 10).

Note-se que aqui se propõe mexer nas bases que estruturam o sistema: a organização interna da universidade; a organização curricular e a relação entre a universidade e o antigo ensino de primeiro e segundo graus, atualmente denominado de Educação Básica.

Mais uma vez nos deparamos com problemas históricos e complexos, que dizem respeito às profundas contradições que perduram no ensino público brasileiro e que, longe de expressarem consensos dentro da comunidade acadêmica, revelam, sim, as diferentes concepções sobre o ensino e a pesquisa, explicitando os diferentes projetos políticos para a educação que convivem contraditoriamente dentro da universidade.

Mas o que não se pode admitir, nesse caso, é que tais questões sejam tratadas apenas como um problema de gestão, como querem os tecnocratas do Conselho Nacional de Educação.

No caso da vinculação entre as escolas de formação e os sistemas de ensino, sabemos que essa batalha é histórica, datando da promulgação do ato adicional de 1834, e que percorreu um longo caminho; contudo, até hoje não se admitiu, de fato, de quem é a responsabilidade pela educação no País.

O fato de se vincular, de forma direta, a formação inicial aos sistemas estaduais e municipais de ensino, vinculando seus currículos, parece ser uma solução muito simplista para uma questão tão delicada que diz respeito às relações entre os estados e a Federação.

Mas não parece ser essa a perspectiva apontada pelo parecer, quando aventa que a desqualificação estaria ligada à falta de oportunidades para o desenvolvimento cultural dos professores, e, para que essa tarefa se realize a contento, caberia à universidade oferecer aos professores da educação básica essa sólida formação cultural:

Muitos dos professores em formação [...] não têm acesso a livros, revistas, vídeos, filmes, 
produções culturais de naturezas diversas. A formação, geralmente, não se realiza em ambientes planejados para serem culturalmente ricos, incluindo leitura, discussões informais, troca de opiniões, participação em movimentos sociais, debates sobre temas atuais, exposições, espetáculos e outras formas de manifestação cultural e profissional. (BRASIL, 2001, p. 21).

Aqui, aparece mais uma vez o desconhecimento dos legisladores no tocante à situação da educação pública brasileira, apesar das inúmeras estatísticas disponíveis.

Em primeiro lugar, resumir o problema da desqualificação do magistério à "falta de oportunidades culturais" é, no mínimo, uma proposição de mau gosto, principalmente quando se refere aos professores da Educação Básica, que vêm sendo submetidos a um processo de desqualificação social e material há décadas.

No entanto, tal afirmação não se sustenta, pois, apesar de todas as distorções no sistema, as universidades públicas brasileiras contam com um mínimo de acervo, laboratórios, bibliotecas, debates acadêmicos, que possibilitam uma formação inicial sólida. O problema, a nosso ver, é o que está se entendendo por esta "sólida formação cultural", juntamente com a função da escola e da universidade.

Ainda no que tange à desqualificação relacionada a não existência de uma base sólida e ampla do ponto de vista cultural, basta nos remetermos aos recentes dados da Organização das Nações Unidas para a Educação, Ciência e a Cultura, e seu estudo realizado em 38 países acerca da situação salarial do magistério - Perfil Estatístico da Profissão de Professor.

Por outro lado, a desqualificação salarial, segundo a presidente da Confederação Nacional dos Trabalhadores em Educação, Juçara Dutra, se constitui em um poderoso fator, pois "[...] a formação dos educadores é feita por eles mesmos. Quem ganha tem de assumir até três empregos e não pode se dedicar. Há relação direta entre salário do professor e desempenho dos alunos". (GOIS, 2002, p. c1).

Apesar de existir, por parte do Governo Federal, o denominado Fundo de Manutenção e Desenvolvimento do Ensino Fundamental e de Valorização do Magistério (Fundef), muitos estados da Federação o desconhecem e se recusam terminantemente a repassar os recursos para o magistério, e o fundo tornou-se uma das maiores fontes de corrupção dos estados e das prefeituras, denunciadas muitas vezes pelas entidades do magistério e pela imprensa de maneira geral.

No que se refere ao documento aqui analisado, este se limita a destacar que a melhoria da qualificação profissional dos professores dependerá das políticas públicas que garantam uma série de recursos básicos, como níveis de remuneração dignos, definição de jornada de trabalho e planos de carreiras compatíveis com o exercício profissional (BRASIL, 2001). 
Outro aspecto importante relativo à qualificação profissional ressaltado pelo parecer, e que vem no bojo das justificativas do documento, diz respeito ao domínio por parte dos professores das tecnologias da informação.

Segundo premissa do documento, nos cursos de formação são raras as iniciativas no sentido de garantir que o futuro professor aprenda a usar, no exercício de sua docência, instrumentos como computador, internet, rádio, videocassete, gravador, softwares educativos, sendo mais raro ainda o uso dessas tecnologias nos diferentes conteúdos curriculares das diferentes áreas do conhecimento (BRASIL, 2001).

Em primeiro lugar, temos de argumentar que a premissa da qual parte o texto não se sustenta em muitos dos seus aspectos.

De fato, não existe a priori, em muitos cursos de licenciatura, disciplinas que discutam o caráter social dessas linguagens baseadas nas tecnologias de informação, mas isso não significa dizer que elas não existam, pois se tratam de poderosos meios de disseminação da informação.

$\mathrm{O}$ que temos de discutir é se essas tecnologias alteram substancialmente a relação entre ensino e aprendizagem, pois em uma sociedade saturada pela comunicação visual se dá pouca importância ao papel desses meios na constituição das relações sociais, ficando esta limitada a cursos superespecializados.

Por outro lado, temos de acrescentar que, do ponto de vista de sua existência social, muitos desses meios já estão consagrados, e alguns deles já possuem mais de um século de existência, como o caso do cinema.

Todavia, o que o parecer não ressalta é o fato de que tais tecnologias de disseminação da informação ainda são muito caras e inacessíveis a quase totalidade dos professores, principalmente aos da Educação Básica.

No que tange à universidade, com vimos em passagem anterior deste texto, os investimentos caíram de tal forma que se torna praticamente impossível pleitear, nos cursos de graduação, laboratórios, equipamentos e meios multimidiáticos para a formação dos futuros professores; e onde tais recursos existem, mantê-los torna-se uma tarefa quase "salomônica", devido, muitas vezes, ao descaso com a coisa pública e à falta de material humano especializado.

A preocupação com a educação tecnológica dos professores não se esgota nos aspectos até aqui levantados. Na sua cruzada desqualificadora da universidade, o documento proclama:

[...] os cursos de formação eximem-se de discutir padrões éticos decorrentes da disseminação da tecnologia e reforçam atitudes de resistência, que muitas vezes disfarçam a insegurança que sentem os formadores e seus alunos professores em formação, para 
imprimir sentido educativo ao conteúdo das mídias, por meio da crítica e da contextualização, que transformam a informação vinculada, necessariamente em conhecimento. (BRASIL, 2001, p. 24).

Mais uma vez, a premissa do documento parece não se justificar. Não se trata de negar que exista, por parte dos docentes, atitudes de resistência e estranhamento quanto ao uso desses meios no contexto educacional; no entanto, o documento não faz nenhuma referência às reflexões dos vários campos de conhecimento sobre a questão, não relativiza o problema, pois, em várias universidades, existem programas de treinamento desenvolvidos para auxiliar professores da rede pública na discussão e no uso desses meios, dando mais uma vez a impressão de que a universidade é a responsável pelas profundas distorções e omissões no tocante à formação dos professores.

Porém, não basta somente imprimir um sentido educativo a esses meios midiáticos, fazendo sua crítica. É o que nos mostra Marcos Silva (1986), ao refletir sobre a relação do trabalho do historiador com tais linguagens. Para esse autor, é preciso pensar sobre as linguagens dependendo de um mercado, garantindo certas modalidades de relações sociais e colaborando na constituição de certa memória social.

Esse autor também acrescenta a necessidade de se trabalhar de forma permanente com as articulações entre tais meios e outras práticas sociais, o que significa enfrentar pelo menos dois outros problemas sobre a situação das linguagens no espaço social de onde elas falam: o estado das linguagens no mundo capitalista e as condições de produção do conhecimento a partir de tais linguagens (SILVA, 1986).

Não basta, portanto, simplesmente acusar os cursos de formação de não apontar e discutir padrões éticos, pois a discussão sobre quem domina quais linguagens põe em cena a questão da luta pelo direito à palavra (e a outras unidades de diferentes linguagens), que, por sua vez, é um elemento da luta dos dominados para se apresentarem na cena histórica como sujeitos.

Todavia, não parece ser a intenção dos legisladores refletir sobre tais significados e continuam seus ataques aos cursos de formação. Em um exemplar exercício de futurismo declararam:

[...] presos às forças tradicionais de interação face a face, na sala de aula real, os cursos de formação ainda não sabem, como preparar professores que vão exercer o magistério nas próximas décadas quando a mediação da tecnologia vai ampliar e diversificar as formas de interagir e compartilhar, em tempos e espaços nunca antes imaginados. (BRASIL, 2001, p. 24).

Bem, como podemos prever, no ano de 2020, estaremos diante de coisas do tipo "Matrix" ou "Minory Report". 
Teremos salas de realidade virtual em todas as universidades e escolas básicas. Cada professor irá dispor de um GPS para se localizar nos espaços virtuais do conhecimento, mas é bem possível que ainda encontremos escolas públicas sem banheiros e bibliotecas e com salas de aula de chão batido pelo País afora.

Por outro lado, não podemos esquecer que, atrás dese exercício de futurismo deslavado, está a imperiosa defesa da famigerada educação a distância, como forma de promover a formação de professores, barateando seus cursos e aligeirando o tempo de formação.

Mas é com base nesse futurismo, saído das páginas mais sofisticadas de certa sociologia, que vemos emergir do parecer o professor do ano 2020:

[...] urge pois, inserir as diversas tecnologias da informação e das comunicações no desenvolvimento dos cursos de formação de professores, preparando-os para a finalidade mais nobre da educação escolar: a gestão e a definição de referências éticas, cientificas e estéticas para troca e negociações de sentido, que acontece especialmente na interação e no trabalho escolar coletivo. Gerir e referir o sentido serão o mais importante e o professor precisará aprender a fazê-lo em ambientes reais e virtuais. (BRASIL, 2001, p. 24).

Ora, enfim cai a máscara. Estamos diante das reais intenções do processo educativo e do papel do futuro professor, e a palavra mágica, saída da cartola dos burocratas, chama-se gestão.

A escola e o professor do futuro são conhecidos como uma grande empresa, na qual, mais importante que formar, é saber gerir, gestar pessoas e conhecimentos, no intuito de anular diferenças e respeitar as individualidades. É o professor e a universidade "just in time".

\section{CONSIDERAÇÕES FINAIS}

Neste trabalho, procuramos analisar a formação de professores, presente nas Diretrizes Curriculares Nacionais para a Formação de Professores da Educação Básica em Nível Superior, curso de Licenciatura Plena, proposta pelo Parecer n⿳o 009/2001, Conselho Nacional de Educação.

Para este artigo, nos ativemos inicialmente ao significado de tais diretrizes no contexto da educação nacional, dentro da estratégia do Estado brasileiro e sua reestruturação produtiva nos ditames de uma política neoliberal.

Em seguida, abordamos o contexto justificador de tais reformas, o problema da qualificação profissional e social do magistério, juntamente com a nova função social da escola e universidade na formação de professores.

Cabe ressaltar que essas diretrizes estão vigorando a cerca de uma década e meia, com repercussões profundas 
no cotidiano escolar e acadêmico. Ao longo da última década, as instituições de ensino superior reformularam seus currículos e aumentaram a carga horária de seus estágios docência. Além disso, criaram-se programas de incentivo à docência, confirmando, assim, o papel estratégico que a formação de professores desempenha na configuração política do Estado.

O quadro não se apresenta animador. O Estado brasileiro, seguindo a lógica dos ajustes neoliberais na economia, acaba de promover um dos maiores cortes orçamentários na educação e saúde do País, cujos resultados são imprevisíveis a curto e médio prazos.

Aliado a esse fator, vivemos mais uma greve nacional dos setores do funcionalismo público federal, incluindo aí o magistério, aguardando seus desdobramentos junto aos poderes instituídos.

Por fim, seguindo a lógica apresentada ao longo de nosso texto, o Estado brasileiro, na figura de seu Ministério da Educação e do Conselho nacional de Educação, acaba de homologar um conjunto de novas Diretrizes Curriculares Nacionais para a formação inicial e continuada do magistério da Educação Básica, cujas bases se encontram no recente Plano Nacional de Educação, e suas metas para a formação de professores, bem como no polêmico documento intitulado "Pátria educadora: a educação básica como projeto de nação", no qual se ressuscitam os velhos fantasmas de nossa educação.

Mas isso é outra história!

\section{REFERÊNCIAS}

BRASIL. Ministério da Educação. Conselho Nacional de Educação. Diretrizes Curriculares Nacionais para a Formação de Professores da Educação Básica, em Nível Superior, Curso de Licenciatura de Graduação Plena. Parecer n. 009/2001, aprovado em 8 de maio de 2001. Brasília: MEC, 2001.

CHAUÍ, Marilena. Ideologia e educação. Revista Educação e Sociedade. São Paulo, v. 2, n. 5, 1980.

Escritos sobre a universidade. São Paulo, UNESP, 2001.

Ideologia neoliberal e universidade. In: OLIVEIRA, Francisco de; PAOLI, Maria Célia. (Org.). Os sentidos da Democracia. Petrópolis: RJ, Vozes, Brasília, NEDIC, 1999.

A mudança a caminho. Folha de São Paulo, São Paulo, 3 de nov. 2002. Tendências e Debates.

DOURADO, Luiz Fernando. Reforma do Estado e as políticas para a Educação Superior no Brasil nos 
anos 90. Revista Educação e Sociedade, Campinas: São Paulo, v. 23, n. 80, set. 2002.

FREITAS, Helena Costa Lopes de. Formação de professores no Brasil: 10 anos de embate entre projetos de formação. Revista Educação e Sociedade, Campinas, São Paulo, v. 23, n. 80, set. 2002.

GOIS, Antônio. Para Unesco, Brasil paga pouco a professor. Folha de São Paulo, São Paulo, 8 dez. 2002. Caderno Cotidiano.

MILANEZ, Francisco. Desenvolvimento sustentável. In: CATTANI, Antônio David. (Org.). A outra economia. Porto Alegre: Veraz, 2003.

OLIVEIRA, Dalila Andrade. Educação Básica: gestão do trabalho e da pobreza. Petrópolis: Vozes, 2000.

ROSSI, Wagner Gonçalves. Capitalismo e Educação. São Paulo: Moraes, 1980.

SANTOMÉ, Jurjo Torres. A reforma educativa e a psicologização dos problemas sociais. Revista Educação e Realidade, Porto Alegre, v. 21, n. 1, 1996.

SILVA, Marcos. O Trabalho da Linguagem. Revista brasileira de História, São Paulo, v. 6, n. 11, 1986.

SILVA, Marcos; ANTONACCI, Maria Antonieta. Vivências da Contramão: produção de saber histórico e processo de trabalho na escola de $1^{\mathrm{O}}$ e $2^{\mathrm{O}}$ graus. Revista Brasileira de História, São Paulo, v. 9, n. 19, fev. 1990.

XAVIER, Maria Elisabeth S. P. Capitalismo e escola no Brasil: a constituição do liberalismo em ideologia educacional e as reformas do ensino - 1931/1961. Campinas, SP: Papirus, 1990. 